\title{
Undermatching Butt Welds in High Strength Steel
}

\author{
Peter Collin \\ Professor \\ Composite Struct. \\ Luleå University of \\ Techn./Ramböll \\ Sweden \\ Pcnbnl@ramboll.com
}

\author{
Mikael Möller \\ $\mathrm{PhD}$ \\ AREVA NP \\ Uddcomb AB \\ Helsingborg, \\ Sweden \\ Mikael.moller@areva.com
}

\author{
Mattias Nilsson \\ MSc \\ Steel Structures. \\ LTU/Ramböll \\ Sweden \\ mnnbnl@ramboll.com
}

\author{
Svante Törnblom \\ MSc \\ Steel Structures. \\ LTU/Banverket \\ Sweden \\ Svante.tornblom@banverke \\ t.se
}

\section{Summary}

The effects of different weld geometries on the mechanical properties of undermatched welds in high strength steel have been studied experimentally. Static tension- and hardness tests have been performed on 30 individual test specimens. Three parameters were chosen to be studied; width- to thickness relation, undermatching level and the ratio between the width of the weld and the thickness of the steel plate (relative thickness). The conclusion is that the weld width and volume has a strong influence on the strength of the joint, this is due to constraint. Fractures were achieved in the base metal for joints undermatched as much as $23 \%$. These seemingly surprising results are explained theoretically using incremental plasticity theory.

Keywords: High strength steel, butt welding, experimental investigation, resistance, plasticity theory.

Significant improvements in steel making technologies, during the last couple of decades, have resulted in "high-performance steel" (HPS) grades, which offer higher performance in tensile strength, toughness and weld ability compared to the traditionally used steel grades. Using these steels generally leads to cost reductions, smaller sized components, lightweight structures and less welding work. The upgrading of steels requests higher demands on reliable welds, in terms of strength, fatigue resistance and safety against brittle fracture.

It is widely common to classify welds as overmatched, evenmatched or undermatched, if the yieldor ultimate strength of the weld metal is, respectively, superior, equal or inferior to that of the base metal. However, in very high strength steel grades, there are no overmatching or matching electrodes available and lower strength electrodes have to be used.

In this paper, the effect of the use of undermatched butt welds in high strength steel under tension is investigated. Welds were produced in coupon plates of high strength, quenched and tempered steel of various thicknesses, using flux cored arc welding (FCAW). To achieve different undermatching levels, two electrodes were used whereas one was the strongest available electrode on the market. The other electrode was chosen to give a certain level of undermatching. To decide the accurate matching levels, the actual strength of the weld metals was evaluated by static tension tests, according to ISO standards.

The joints undergoing the tests consisted of two coupons $(200 \times 1000 \mathrm{~mm})$, where joint preparation and welding was performed on the longer side. A number of 30 flat tensile test specimens were then extracted from the welded joints and tensile tests was carried out. A photograph of one of the test specimens from is shown below. 


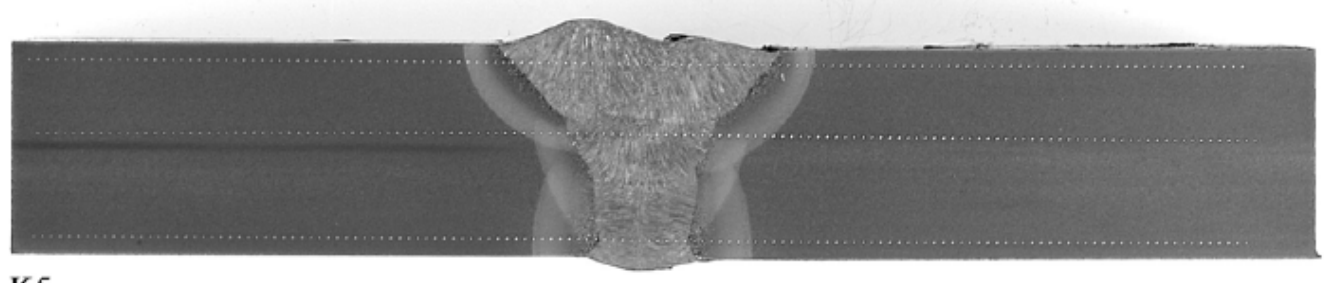

K5

$10 \mathrm{~mm}$

Figure 1. Longitudinal section through butt welded plates in High Strength Steel. Plate thickness 12 $\mathrm{mm}$, nominal strength of base metal $f_{y}=1100 \mathrm{MPa}$.

Three parameters were chosen to be studied;

- Width- to thickness relation.

- Undermatching level.

- Relative thickness, i.e. the ratio between the width of the weld and the thickness of the steel plate.

As expected, both the yield strength and ultimate strength was shown to increase with increasing specimen width. It is noteworthy that the ratio between the yield and ultimate strength also was found to increase with increasing width.

For the undermatching studies, it was clear that the strength of the joints welded with the strongly undermatching wire was well above the strength of the wire material itself, thus showing the effect of triaxiality and strain hardening. A ratio between the joint strength and the base metal strength was calculated, indicating how close the joint came to achieving the base metal's strength. The global strength of the joints for Weldox 960 steel and PZ6149 electrodes was found to be governed by the base plate strength. On the other hand, when the same steel plate was welded with the weaker type of electrode, all samples failed in the weld metal.

For the last parameter studied, as expected, the strength was shown to decrease with increasing relative thickness. In almost all the undermatch cases, and for ratios between the widths of the weld to the thickness of the plate lower than unity, an apparent increase in the material strength was observed due to constraint

The performed tests show that it is possible, for the global strength of an undermatched test specimen to achieve the base plate strength. Failure was found to occur in the base metal even with an undermatching index as low as $77 \%$. It is also shown that if the thickness of the steel plate is kept constant and only the specimen width is increased, the global strength of the joint increases with the width of the specimens. Both the yield strength and ultimate strength increased with the specimen width, but the difference between them got smaller. This is due to constraint of the surrounding base metal which is the underlying mechanism of the large joint resistance.

When the soft weld starts to deform, the adjacent, unyielded base plate, constrains this deformation. The weld develops tension in the width \& thickness directions in addition to the longitudinal direction. When the weld experiences tension in three material directions, the mean stress or hydrostatic stress in the weld is increased. Yielding of a material is governed by the Von-Mises Yield Criterion. Therefore, as the hydrostatic stress is increased by constraint, the magnitudes of the deviatory stresses which govern yielding are not increased accordingly. Thus because of constraint, larger axial stresses are required to further increase plastic strain. The mechanics of this phenomenon may be demonstrated by plasticity theory. That is mathematically done in this report. 


\section{Undermatching Butt Welds in High Strength Steel}

\author{
Peter Collin \\ Professor \\ Composite Struct. \\ Luleå University of \\ Techn./Ramböll \\ Sweden \\ Pcnbnl@ramboll.com
}

\author{
Mikael Möller \\ $\mathrm{PhD}$ \\ AREVA NP \\ Uddcomb AB \\ Helsingborg, \\ Sweden \\ Mikael.moller@areva.com
}

\author{
Svante Törnblom \\ MSc \\ Steel Structures. \\ LTU/Banverket \\ Sweden \\ Svante.tornblom@banve \\ rket.se
}

MSc

Steel Structures.

LTU/Ramböll

Sweden

Mnnbnl@ramboll.com

\section{Summary}

The effects of different weld geometries on the mechanical properties of undermatched welds in high strength steel have been studied experimentally. Static tension- and hardness tests have been performed on 30 individual test specimens. Three parameters were chosen to be studied; width- to thickness relation, undermatching level and the ratio between the width of the weld and the thickness of the steel plate (relative thickness). The conclusion is that the weld width and volume has a strong influence on the strength of the joint, this is due to constraint. Fractures were achieved in the base metal for joints undermatched as much as $23 \%$. These seemingly surprising results are explained theoretically using incremental plasticity theory.

Keywords: High strength steel, butt welding, experimental investigation, resistance, plasticity theory.

\section{Introduction}

Significant improvements in steel making technologies, during the last couple of decades, have resulted in "high-performance steel" (HPS) grades, which offer higher performance in tensile strength, toughness and weld ability compared to the traditionally used steel grades. Using these steels generally leads to cost reductions, smaller sized components, lightweight structures and less welding work. Most importantly, these new grades contribute to a sustainable environment due to improved durability properties and reduced material use, [1].

The upgrading of steels requests higher demands on reliable welds, in terms of strength, fatigue resistance and safety against brittle fracture. The question is how to meet these requirements and thus how to match the weld metal with the parent metal. It is common to classify welds as overmatched, evenmatched or undermatched, if the yield- or ultimate strength of the weld metal is, respectively, superior, equal or inferior to that of the base metal. Overmatched welds are generally used in structural components under tensile loads, in order to guarantee the transfer of yielding to the base material, in case of plastic flow of the component.

The difference between the mechanical properties of the parent metal and the weld metal increases, the weld metal, contrary to the parent metal, is still a cast alloy whose strength mainly depends on its chemistry, [2]. In very high strength steel grades, there are no overmatching or matching electrodes available and lower strength electrodes have to be used.

\section{Experimental procedure}

Welds were produced in coupon plates of high strength, quenched and tempered steel of various thicknesses, using flux cored arc welding (FCAW). To avoid using defective material, all joints were radiographed. The studied base metals come from SSAB's WELDOX-family of construction steels. Two different WELDOX 1100 plates (5,5 and $12 \mathrm{~mm}$ thick) and one WELDOX 960 plate (6 $\mathrm{mm}$ thick), were used. The mechanical and chemical properties of the steels are presented in Table 1 and Table 2 below.

The joints consisted of two coupons $(200 \times 1000 \mathrm{~mm})$, where joint preparation and welding was performed on the longer side. Single V-joint preparation was used for all specimens. The design of the different joints was done according to Figure 1. In total 7 joints were used from 5 joint types. Joint type 1-4 is of WELDOX 1100 and joint type 5 is made from WELDOX 960. 
Table 1. Mechanical properties of the steel plates used in the tests.

\begin{tabular}{||l|c|c|c|c||}
\hline \hline Base metal & $\mathrm{R}_{\mathrm{p} 0,2}[\mathrm{MPa}]$ & $\mathrm{R}_{\mathrm{m}}[\mathrm{MPa}]$ & $\mathrm{A} 5[\%]$ & $\mathrm{CVL}(\mathrm{J})-40^{\circ}$ \\
\hline WELDOX 960E $(6 \mathrm{~mm})$ & 1054 & 1099 & 12 & 60 \\
\hline WELDOX 1100E (12 mm) & 1193 & 1397 & 10 & 64 \\
\hline WELDOX 1100E $(5,5 \mathrm{~mm})$ & 1361 & 1458 & 10 & 37 \\
\hline
\end{tabular}

Table 2. Chemical composition [\% of mass] for the steel plates used in the tests.

\begin{tabular}{||l|l|l|l|l|l|l|l|l|l||}
\hline Steel & $\mathrm{C}$ & $\mathrm{Si}$ & $\mathrm{Mn}$ & $\mathrm{Mo}$ & $\mathrm{V}$ & $\mathrm{Ti}$ & $\mathrm{Cr}$ & $\mathrm{Ni}$ & $\mathrm{CE}$ \\
\hline WELDOX 960E (6 mm) & 0.17 & 0.22 & 1.21 & 0.587 & 0.043 & 0.003 & 0.20 & 0.04 & - \\
\hline WELDOX 1100E (12 mm) & 0.17 & 0.21 & 0.88 & 0.386 & 0.019 & 0.003 & 0.48 & 1.29 & - \\
\hline WELDOX 1100E (5.5 mm) & 0.16 & 0.21 & 0.88 & 0.391 & 0.022 & 0.003 & 0.50 & 1.29 & - \\
\hline
\end{tabular}

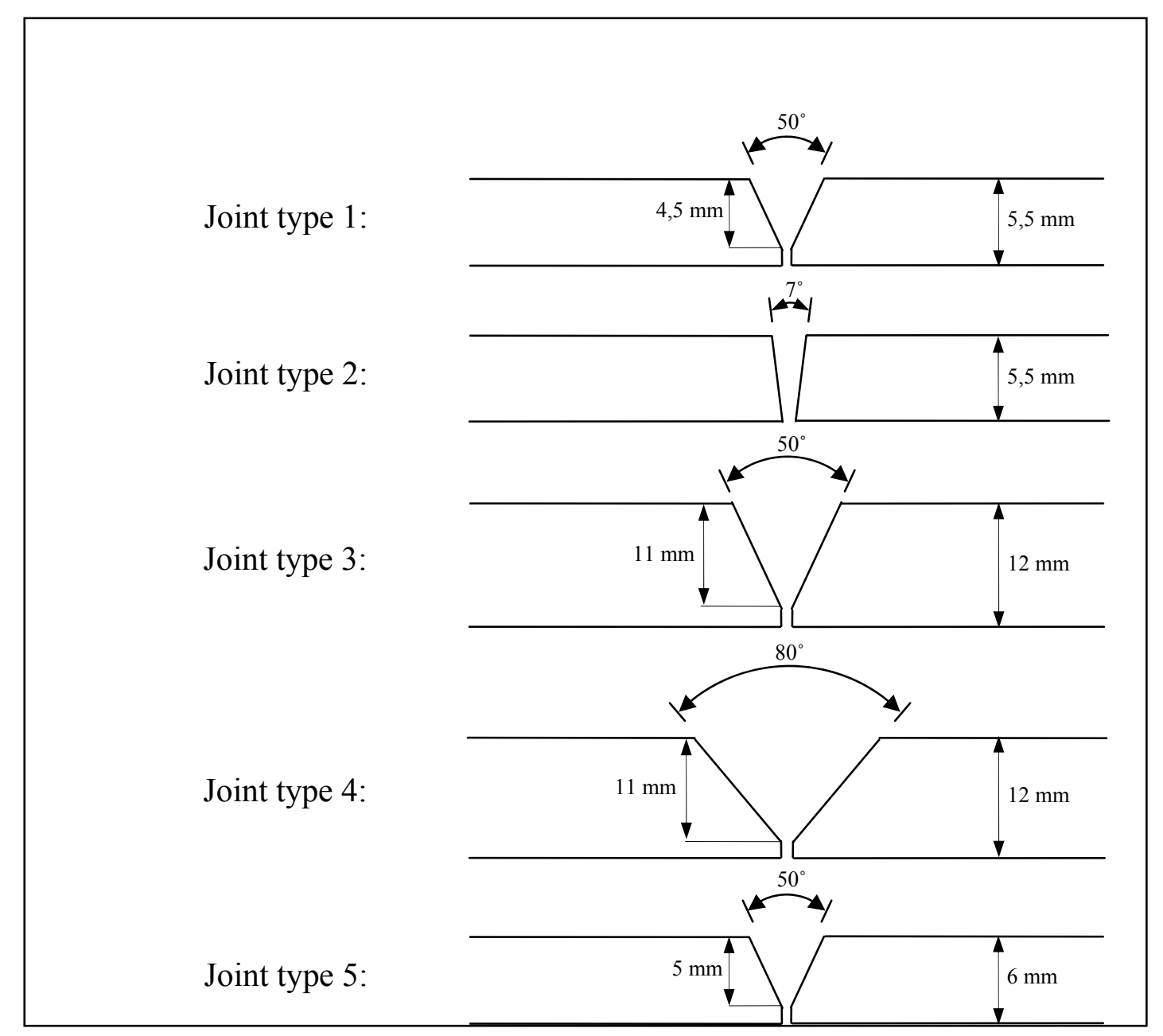

Figure 2. Joint designs, single V-joint preparation.

To achieve different undermatching levels, two electrodes were used; one (Filarc PZ 6149) was the strongest available electrode on the market and the other (Filarc PZ 6145) was chosen to give a certain level of undermatch. Both welding wires had a diameter of 1,2 mm. It was crucial to know the actual strength of the weld metal, to be able to accurately decide the matching levels. 
Therefore, static tension tests, according to ISO standards, were performed on both weld metals. The results from these tests are given in Table 3 below. The aim was to keep the cooling-time between 800 and $500^{\circ} \mathrm{C}\left(\Delta \mathrm{t}_{8 / 5}\right)$ constant at 10 seconds, which would be in the middle of the parameter box for both WELDOX 960 and 1100. Table 4 shows the welding parameters used for the different joints.

Table 3. Mechanical properties of the weld metals - measured.

\begin{tabular}{||l|c|c|c|c|c||}
\hline \hline Welding wire & $\mathrm{R}_{\mathrm{p} 0,2}[\mathrm{MPa}]$ & $\mathrm{R}_{\mathrm{p} 0,2}{ }^{\text {ave }}[\mathrm{MPa}]$ & $\mathrm{R}_{\mathrm{m}}[\mathrm{MPa}]$ & $\mathrm{R}_{\mathrm{m}}{ }^{\text {ave }}[\mathrm{MPa}]$ & $\mathrm{A} 5[\%]$ \\
\hline Filarc PZ6145 & $618,491,608$ & 572 & $696,688,689$ & 691 & $23,21,23$ \\
\hline Filarc PZ6149 & $804,844,797$ & 815 & $1001,1015,1028$ & 1015 & $17,17,14$ \\
\hline
\end{tabular}

Table 4. Welding parameters for the different joints.

\begin{tabular}{||l|c|c|c||}
\hline Joint No./Method & $\mathrm{Q}[\mathrm{kJ} / \mathrm{mm}]$ & $\begin{array}{c}\text { No. of } \\
\text { Passes }\end{array}$ & $\begin{array}{c}\text { Initial } \\
\text { Temp } \\
{\left[{ }^{\circ} \mathrm{C}\right]}\end{array}$ \\
\hline 1/FCAW & $0,60-0,70$ & 3 & 20 \\
\hline 2/FCAW & $0,61-0,66$ & 3 & 20 \\
\hline 3/FCAW & $0,60-0,66$ & 3 & 20 \\
\hline 4/FCAW & $0,60-0,70$ & 3 & 20 \\
\hline 5/FCAW & $0,60-0,70$ & 3 & 20 \\
\hline 6/FCAW & 1,00 & 4 & 160 \\
\hline 7/FCAW & 1,00 & 7 & 160 \\
\hline \hline
\end{tabular}

Flat tensile test specimens were extracted from the welded joints. Each combination of testing parameters embodied three different specimens. The standard web width was set to $24 \mathrm{~mm}$. Tensile tests were carried out at room temperature in two different material testing machines. Most tests were done in a $600 \mathrm{kN}$ capacity, semi-automatic Zwick testing machine.

For specimens with wider web, an automatic $1000 \mathrm{kN}$ capacity machine was used. When the tensile tests were finished, the specimens were etched and photographed for evaluation of the fracture location. One macro test sample was taken from each joint. The test was examined for:

i) Hardness tests across the welded joint according to HV 5, the distance between indentations was, in all cases, $0,5 \mathrm{~mm}$ (one row of indentations was placed $1 \mathrm{~mm}$ below the top-side of the joint, one row of indentations was placed along the centreline of the plate thickness, and one row of indentations was placed $1 \mathrm{~mm}$ over the root-side of the joint).

ii) One macro photograph, in scale 1:1, was taken for each joint.

\section{Results and discussion}

\subsection{Test results}

Results from the static tension tests of the welded joints are given in Table 5. The yield strength, ultimate strength, elongation and failure position has been evaluated for every specimen. Contraction was only evaluated towards the end of the test series. Table 6 shows results from the hardness tests. Only one side of the test sample was evaluated, because of symmetry. 
Table 5. Mechanical properties of the welded joints.

\begin{tabular}{|c|c|c|c|c|c|c|c|c|c|c|c|}
\hline 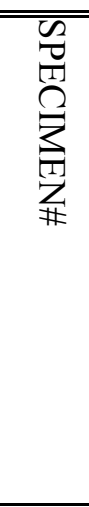 & 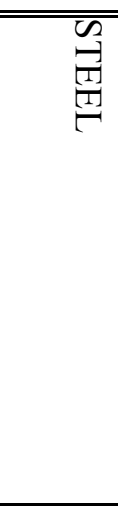 & 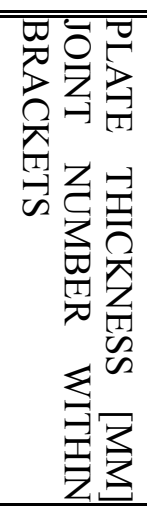 & 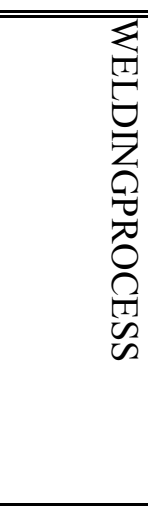 & 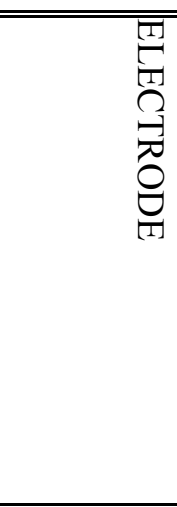 & 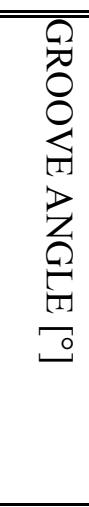 & 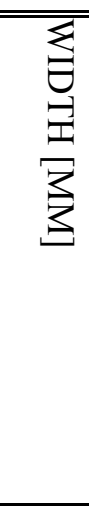 & 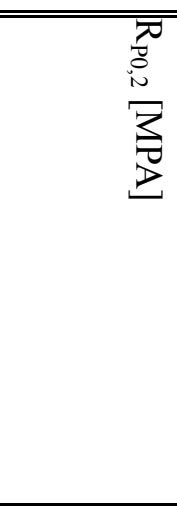 & $\begin{array}{l}\mathbf{2} \\
3 \\
3 \\
3 \\
3\end{array}$ & 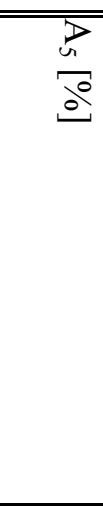 & $\frac{N}{\Omega^{\circ}}$ & 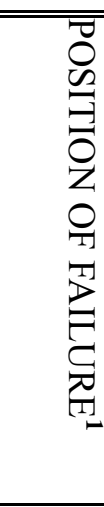 \\
\hline 1 & 960 & 6 & FCAW & PZ 6149 & 50 & 24 & 906,253 & 982,58 & 11 & & $\mathrm{BM}$ \\
\hline 2 & 960 & 6 & FCAW & PZ 6149 & 50 & 24 & 1047,03 & 1103,67 & 11 & & $\mathrm{BM}$ \\
\hline 3 & 960 & 6 & FCAW & PZ 6149 & 50 & 24 & 1004,12 & 1077 & 9 & & $\mathrm{BM}$ \\
\hline 4 & 1100 & 5,5 & FCAW & PZ 6145 & 50 & 24 & 775,144 & 915,705 & 6 & & WM \\
\hline 5 & 1100 & 5,5 & FCAW & PZ 6145 & 50 & 24 & 805,419 & 942,756 & 5 & & HAZ \\
\hline 6 & 1100 & 5,5 & FCAW & PZ 6145 & 50 & 24 & 823,475 & 979,665 & 6 & & HAZ \\
\hline 7 & 960 & 6 & FCAW & PZ 6145 & 50 & 24 & 805,082 & 931,619 & 3 & & WM \\
\hline 8 & 960 & 6 & FCAW & PZ 6145 & 50 & 24 & 827,83 & 934,952 & 5 & & WM \\
\hline 9 & 960 & 6 & FCAW & PZ 6145 & 50 & 24 & 820,137 & 921,05 & 4 & & $\mathrm{WM}$ \\
\hline 10 & 1100 & $5,5(2)$ & FCAW & PZ 6149 & 50 & 12 & 1002,7 & 1108,39 & 6 & & WM \\
\hline 11 & 1100 & $5,5(2)$ & FCAW & PZ 6149 & 50 & 12 & 1003,68 & 1115,98 & 5 & & $\mathrm{BM}$ \\
\hline 12 & 1100 & $5,5(2)$ & FCAW & PZ 6149 & 50 & 12 & 968,408 & 1086,67 & 8 & & WM \\
\hline 13 & 1100 & $5,5(2)$ & FCAW & PZ 6149 & 50 & 24 & 1069,16 & 1136,81 & 7 & & HAZ \\
\hline 14 & 1100 & $5,5(2)$ & FCAW & PZ 6149 & 50 & 24 & 1032,18 & 1128,15 & 8 & & HAZ \\
\hline 15 & 1100 & $5,5(2)$ & FCAW & PZ 6149 & 50 & 24 & 1031,57 & 1123,66 & 8 & & WM \\
\hline 16 & 1100 & $5,5(2)$ & FCAW & PZ 6149 & 50 & 48 & 1108,12 & 1169,26 & 6 & & WM \\
\hline 17 & 1100 & $5,5(2)$ & FCAW & PZ 6149 & 50 & 48 & 1105,03 & 1190,79 & 4 & & WM \\
\hline 18 & 1100 & $5,5(2)$ & FCAW & PZ 6149 & 50 & 48 & 1142,87 & 1184,35 & 6 & & WM \\
\hline 19 & 1100 & $5,5(2)$ & FCAW & PZ 6149 & 50 & 6 & 939,607 & 1063,48 & 9,3 & & WM \\
\hline 20 & 1100 & $5,5(2)$ & FCAW & PZ 6149 & 50 & 6 & 967,265 & 1069,42 & 11,4 & & $\mathrm{BM}$ \\
\hline 21 & 1100 & $5,5(2)$ & FCAW & PZ 6149 & 50 & 6 & 947,322 & 1075,32 & 12 & & $\mathrm{BM}$ \\
\hline 22 & 1100 & $5,5(1)$ & FCAW & PZ 6149 & 50 & 96 & 1159 & 1193 & 3 & & HAZ \\
\hline 23 & 1100 & $5,5(1)$ & FCAW & PZ 6149 & 50 & 96 & 1148 & 1177 & 3 & & HAZ \\
\hline 24 & 1100 & $5,5(1)$ & FCAW & PZ 6149 & 50 & 96 & 1172 & 1205 & 3 & & $\mathrm{BM}$ \\
\hline 25 & 1100 & 12 & FCAW & PZ 6149 & 50 & 24 & 1012,79 & 1090,44 & 7 & 23 & HAZ \\
\hline 26 & 1100 & 12 & FCAW & PZ 6149 & 50 & 24 & 1071,53 & 1099,01 & 5 & 24 & HAZ \\
\hline 27 & 1100 & 12 & FCAW & PZ 6149 & 50 & 24 & 992,255 & 1089,5 & 7 & 23 & HAZ \\
\hline 28 & 1100 & 12 & FCAW & PZ 6149 & 80 & 24 & 939,581 & 1031,16 & 7 & 23 & HAZ \\
\hline 29 & 1100 & 12 & FCAW & PZ 6149 & 80 & 24 & 834,008 & 1038,4 & 7 & 29 & HAZ \\
\hline 30 & 1100 & 12 & FCAW & PZ 6149 & 80 & 24 & 934,168 & 1030,46 & 6 & 22 & HAZ \\
\hline
\end{tabular}

${ }^{1} \mathrm{BM}=$ Base Metal, $\mathrm{WM}=$ Weld Metal, HAZ $=$ Heat Affected Zone 
Since the hardness of a metal is approximately proportional to the ultimate strength of the material, hardness values from Table 6 have been translated into ultimate strengths below. If these values are compared to the ones in Table 1 and Table 3 it is obvious that they indicate the strength fairly well.

$$
\begin{array}{ll}
\text { Wx } 1100(5,5 \mathrm{~mm})=446 \mathrm{HV} 5 & \rightarrow \mathrm{f}_{\mathrm{u}}=1338 \mathrm{MPa} \\
\text { Wx } 1100(12 \mathrm{~mm})=418 \mathrm{HV} 5 & \rightarrow \mathrm{f}_{\mathrm{u}}=1254 \mathrm{MPa} \\
\text { Wx } 960(6 \mathrm{~mm})=348 \mathrm{HV} 5 & \rightarrow \mathrm{f}_{\mathrm{u}}=1044 \mathrm{MPa} \\
\text { PZ6149 }=347 \mathrm{HV} 5 & \rightarrow \mathrm{f}_{\mathrm{u}}=1041 \mathrm{MPa} \\
\text { PZ6145 }=240 \mathrm{HV} 5 & \rightarrow \mathrm{f}_{\mathrm{u}}=720 \mathrm{MPa}
\end{array}
$$

Table 6. Hardness test according to HV 5, the distance between indentations was 0,5 $\mathrm{mm}$.

\begin{tabular}{||l|l|l|l|l|l|l|l|l|l|l|l|l||}
\hline $\begin{array}{l}\text { Test } \\
\text { No. }\end{array}$ & $\begin{array}{l}\text { Top } \\
\text { BM }\end{array}$ & $\begin{array}{l}\text { Top } \\
\text { HAZ }_{\text {min }}\end{array}$ & $\begin{array}{l}\text { Top } \\
\text { HAZ }_{\text {max }}\end{array}$ & $\begin{array}{l}\text { Top } \\
\text { WM }\end{array}$ & $\begin{array}{l}\text { Centre } \\
\text { BM }\end{array}$ & $\begin{array}{l}\text { Centre } \\
\text { HAZ }_{\text {min }}\end{array}$ & $\begin{array}{l}\text { Centre } \\
\text { HAZ }_{\text {max }}\end{array}$ & $\begin{array}{l}\text { Centre } \\
\text { WM }\end{array}$ & $\begin{array}{l}\text { Root } \\
\text { BM }\end{array}$ & $\begin{array}{l}\text { Root } \\
\text { HAZ }_{\text {min }}\end{array}$ & $\begin{array}{l}\text { Root } \\
\text { HAZ }_{\max }\end{array}$ & $\begin{array}{l}\text { Root } \\
\text { WM }\end{array}$ \\
\hline $1-1$ & 458 & 315 & 449 & 355 & 449 & 314 & 437 & 361 & 465 & 310 & 465 & 351 \\
\hline $1-2$ & 453 & 318 & 437 & 369 & 439 & 315 & 432 & 362 & 464 & 307 & 454 & 334 \\
\hline 2 & 352 & 332 & 410 & 373 & 346 & 323 & 384 & 344 & 350 & 303 & 356 & 344 \\
\hline 3 & 441 & 314 & 406 & 245 & 427 & 282 & 369 & 237 & 434 & 252 & 365 & 235 \\
\hline 4 & 346 & 307 & 382 & 247 & 343 & 303 & 356 & 240 & 348 & 287 & 356 & 234 \\
\hline 5 & 420 & 302 & 398 & 368 & 423 & 290 & 398 & 353 & 422 & 276 & 400 & 326 \\
\hline 6 & 416 & 304 & 402 & 378 & 414 & 280 & 402 & 326 & 410 & 265 & 396 & 289 \\
\hline \hline
\end{tabular}

\subsection{Width- to thickness relation}

The values presented in Table 7 - Table 9 are the average values of the three individual specimens tested for each set of parameters. Both the yield strength and ultimate strength increases with increasing specimen width, as expected. It is noteworthy that the ratio between yield and ultimate strength also increases with increasing width.

Table 7. Mechanical properties from specimens where the width- to thickness relation was studied

\begin{tabular}{||l|l|l|l|l|l||}
\hline \hline Specimen width & $\mathrm{f}_{\mathrm{y}}[\mathrm{MPa}]$ & $\mathrm{f}_{\mathrm{u}}[\mathrm{MPa}]$ & $\mathrm{A}_{5}[\mathrm{MPa}]$ & $\mathrm{f}_{\mathrm{y}} / \mathrm{f}_{\mathrm{u}}$ & Fracture Location \\
\hline $6 \mathrm{~mm}$ & 951,4 & 1069,4 & 10,9 & 0,89 & WM/BM/BM \\
\hline $12 \mathrm{~mm}$ & 991,6 & 1103,7 & 6,3 & 0,90 & WM/BM/WM \\
\hline $24 \mathrm{~mm}$ & 1044,3 & 1126,6 & 7,7 & 0,93 & HAZ/HAZ/WM \\
\hline $48 \mathrm{~mm}$ & 1118,7 & 1181,5 & 5,3 & 0,95 & WM/WM/WM \\
\hline $96 \mathrm{~mm}$ & 1159,7 & 1191,7 & 3 & 0,97 & HAZ/HAZ/HAZ \\
\hline
\end{tabular}

\subsection{Undermatching}

The strength of the joints welded with the strongly undermatching wire is well above the strength of the wire, which is $691 \mathrm{MPa}$ (PZ6145). This shows the effect of triaxiality and strain hardening. The ratio between the joint strength and the base metal strength indicates how close the joint came to achieving the base metal's strength. The fracture location in the joints of Weldox 960 steel and PZ6149 electrode shows that the global strength of the joint is governed by the base plate strength. On the other hand, when the same steel plate was welded with the weaker electrode all samples failed in the weld metal. 
Table 8. Mechanical properties from specimens where the undermatching effect was studied.

\begin{tabular}{|c|c|c|c|c|c|c|c|c|c|}
\hline \multirow{2}{*}{$\begin{array}{l}\text { Steel/ } \\
\text { Electrode }\end{array}$} & \multirow{2}{*}{$\mathrm{f}_{\mathrm{y}}$} & \multirow{2}{*}{$\mathrm{f}_{\mathrm{u}}$} & \multirow{2}{*}{$\mathrm{f}_{\mathrm{y}} / \mathrm{f}_{\mathrm{u}}$} & \multirow{2}{*}{$\mathrm{A}_{5}$} & \multirow{2}{*}{$\begin{array}{l}\text { Fracture- } \\
\text { Location }\end{array}$} & \multirow{2}{*}{$\mathrm{f}_{\mathrm{u}}^{\text {joint }} / \mathrm{f}_{\mathrm{u}}^{\mathrm{BM}}$} & \multicolumn{2}{|c|}{ 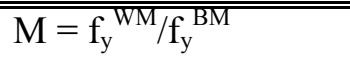 } & \multirow{2}{*}{$\begin{array}{l}\begin{array}{l}M \\
f_{u}^{W M} / f_{u}^{B M}\end{array} \\
\text { Obs }\end{array}$} \\
\hline & & & & & & & Typ. $^{2}$ & Obs. $^{3}$ & \\
\hline $960 / 6149$ & 985,8 & 1054,4 & 0,93 & 10,3 & $\mathrm{BM} / \mathrm{BM} / \mathrm{BM}$ & $\begin{array}{l}1054 / 1094 \\
=0,96\end{array}$ & $\begin{array}{l}890 / 1054 \\
=0,84\end{array}$ & $\begin{array}{l}815 / 1054 \\
=0,77\end{array}$ & $\begin{array}{l}1015 / 1099 \\
=0,92\end{array}$ \\
\hline $1100 / 6145$ & 801,3 & 946,0 & 0,85 & 5,7 & WM/HAZ/HAZ & $\begin{array}{l}946 / 1458 \\
=0,65\end{array}$ & $\begin{array}{l}500 / 1361 \\
=0,37\end{array}$ & $\begin{array}{l}572 / 1361 \\
=0,42\end{array}$ & $\begin{array}{l}691 / 1458 \\
=0,47\end{array}$ \\
\hline $960 / 6145$ & 817,7 & 929,2 & 0,88 & 4,0 & WM/WM/WM & $\begin{array}{l}929 / 1094 \\
=0,85\end{array}$ & $\begin{array}{l}500 / 1054 \\
=0,47\end{array}$ & $\begin{array}{l}572 / 1054 \\
=0,54\end{array}$ & $\begin{array}{l}691 / 1099 \\
=0,63\end{array}$ \\
\hline $1100 / 6149$ & 1044,3 & 1126,6 & 0,93 & 7,7 & $\mathrm{HAZ} / \mathrm{HAZ} / \mathrm{WM}$ & $\begin{array}{l}1127 / 1458 \\
=0,77\end{array}$ & $\begin{array}{l}890 / 1361 \\
=0,65\end{array}$ & $\begin{array}{l}815 / 1361 \\
=0,60\end{array}$ & $\begin{array}{l}1015 / 1458 \\
=0,70\end{array}$ \\
\hline
\end{tabular}

\subsection{Relative thickness}

There were some problems to fabricate specimens with a low relative thickness ( $7^{\circ}$ groove angle). The ambition was to use a low energy weld method to get a small weld metal volume, but it was not possible to weld that small groove angles even with this method. Only two groove angles, to compare, were accomplished. As expected the strength decreases with increasing relative thickness. In almost all the undermatch cases and for ratios between the widths of the weld to the thickness of the plate lower than unity, an apparent increase in the material strength is observed due to constraint. This is developed into some depth below.

Table 9. Mechanical properties of specimens where the effect of relative thickness was studied.

\begin{tabular}{||l|l|l|l|l|l|l||}
\hline \hline Groove Angle $\left[^{\circ}\right]$ & Relative Thickness & $\mathrm{f}_{\mathrm{y}}$ & $\mathrm{f}_{\mathrm{u}}$ & $\mathrm{A}_{5}$ & $\mathrm{f}_{\mathrm{y}} / \mathrm{f}_{\mathrm{u}}$ & Fracture-Location \\
\hline 50 & 0,93 & 1025,5 & 1093,0 & 6,3 & 0,94 & HAZ/HAZ/HAZ \\
\hline 80 & 1,68 & 902,6 & 1033,3 & 6,7 & 0,87 & HAZ/HAZ/HAZ \\
\hline
\end{tabular}

\subsection{Theoretical considerations of the results}

The mechanical behaviour of the joint is at first sight somewhat surprising. The underlying mechanism of the large joint resistance lies within the constraint offered by the base metal. The mechanics may be demonstrated by plasticity theory as follows. Consider a narrow weld of an undermatching metal. Obviously, since the Young's modulus and the Poisson ratio of the weld metal and the base metal are the same, the initial behaviour at uniaxial tension is the same as that of the base metal alone and the only stress present in the joint is the uniaxial one. Now, at a certain load the weld metal reaches its yield strength and plastic strains initiate. However, due to the constraints from the surrounding base metal, the transverse strain in the weld metal must equal that of the base metal. Now, from incremental plasticity theory, the plastic strain increments are written

$$
d \varepsilon_{i j}^{p}=\frac{9 s_{r s} d \sigma_{r s}}{4 H_{p} \sigma_{e}^{2}} s_{i j}
$$

\footnotetext{
${ }^{2}$ Typical values from the manufactor

${ }^{3}$ Measured values from our test series
} 
in which $\sigma_{e}$ denotes the von Mises effective stress, $H_{p}$ denotes the plastic modulus and $s_{i j}$ denotes the deviatoric stress components. Denoting the longitudinal stress $\sigma_{x}$ and postulating symmetry with respect to stress and strain in the perpendicular directions - implying the limiting case of an infinitely narrow weld and infinitely strong base material- yields

$$
\begin{aligned}
& d \varepsilon_{x}^{p}=\frac{9\left(s_{x} d \sigma_{x}+2 s_{y} d \sigma_{y}\right)}{4 H_{p} \sigma_{e}^{2}} s_{x} \\
& d \varepsilon_{y}^{p}=\frac{9\left(s_{x} d \sigma_{x}+2 s_{y} d \sigma_{y}\right)}{4 H_{p} \sigma_{e}^{2}} s_{y}
\end{aligned}
$$

In which the strains and stresses in the z-direction are replaced by the equal quantities in the $y$ direction. Collecting also the elastic parts yields the total strain increments

$$
\begin{aligned}
& d \varepsilon_{x}=\frac{d \sigma_{x}}{E}-\frac{2 v d \sigma_{y}}{E}+\frac{9\left(s_{x} d \sigma_{x}+2 s_{y} d \sigma_{y}\right)}{4 H_{p} \sigma_{e}^{2}} s_{x} \\
& d \varepsilon_{y}=\frac{(1-v) d \sigma_{y}}{E}-\frac{v d \sigma_{x}}{E}+\frac{9\left(s_{x} d \sigma_{x}+2 s_{y} d \sigma_{y}\right)}{4 H_{p} \sigma_{e}^{2}} s_{y}
\end{aligned}
$$

Now, due to the constraint from the base material it must hold for the weld metal as for the base metal

$$
d \varepsilon_{y}=-\frac{v d \sigma_{x}}{E}
$$

From eq (5) and (6) it is obtained

$$
\frac{(1-v) d \sigma_{y}}{E}+\frac{9\left(s_{x} d \sigma_{x}+2 s_{y} d \sigma_{y}\right)}{4 H_{p} \sigma_{e}^{2}} s_{y}=0
$$

or solved for the transversal stress increment

$$
d \sigma_{y}=-\frac{\frac{9 s_{x} s_{y} d \sigma_{x}}{4 H_{p} \sigma_{e}^{2}}}{\frac{(1-v)}{E}+\frac{9 s_{y} s_{y}}{2 H_{p} \sigma_{e}^{2}}}=d \sigma_{z}
$$

Integration of eq (8) defines the weld response completely for a weld metal with any stress-strain curve. Now, consider for illustrative purposes the special case of ideal plasticity meaning zero plastic modulus. For ideal plasticity eq (8) turns into

$$
d \sigma_{y}=-\frac{2 s_{x} d \sigma_{x}}{4 s_{y}}=d \sigma_{z}
$$


At yield it holds $s_{y}=-s_{x} / 2$ and hence the increments are obtained as $d \sigma_{y}=d \sigma_{x}=d \sigma_{z}$ which means that the stress state following initial yield is simply climbing in stress space parallel to the hydrostatic axis. As a direct consequence, the longitudinal stress can increase without any increase of effective stress in the weld metal. For the considered limiting case, the strength of the weld joint is hence entirely unaffected by the fact that the strength of the weld metal is lesser than the strength of the base metal. In real life, this effect is obviously present but of course not unlimited. However, the mathematics above illustrates analytically the physics of the obtained experimental results. Numerical studies of this phenomenon are performed in [3].

\section{Conclusions}

It is definitely possible, for the global strength of an undermatched test specimen to achieve the base plate strength. For example specimens made from Weldox 960 steel and PZ6149 weld metal. All three of these specimens failed in the base metal although the observed undermatching index was as low as $77 \%$. Other sources, [4], claims that the maximum tolerable undermatch is about 10$15 \%$. Under this level, plastic flow is induced in the weakest zone which reduces strength and ductility of the joint. We never managed to achieve the base plate strength in Weldox 1100 steel even though the electrode used was the strongest available on the market. These specimens failed in HAZ and had a matching index of 0,60 . This means that it would be hard to reach the base plate strength for even higher strength steels (Weldox 1300) loaded in pure tension.

If the thickness of the steel plate is kept constant and only the specimen width is increased, the global strength of the joint increases with the width of the specimens. Both the yield strength and ultimate strength increased with the specimen width, but the difference between them got smaller. This is due to constraint. When the soft weld starts to deform, the adjacent, unyielded base plate, constrains this deformation. The weld develops tension in the width \& thickness directions in addition to the longitudinal direction. When the weld experiences tension in three material directions, the mean stress or hydrostatic stress in the weld is increased. Yielding of a material is governed by the Von-Mises Yield Criterion. Therefore, as the hydrostatic stress is increased by constraint, the magnitudes of the deviatory stresses which govern yielding are not increased accordingly. Thus because of constraint, larger axial stresses are required to further increase plastic strain.

\section{References}

[1] Use and application of high-performance steels for steel structures, International Association for Bridge and Structural Engineering (IABSE). (2005). ISBN 3-85748-113-7.

[2] BLOMQVIST, A. Mismatch in High Strength Steel Weldments. Application Research and Development, SSAB Oxelösund, 1995.

[3] FERNANDES, J.V., LOUREIRO, A., MENEZEZ, L.F. AND RODRIGUES, D.M., Numerical study of the plastic behaviour in tension of welds in high strength steels, International Journal of Plasticity 20, pp. 1-18

[4] DEXTER, R.J., Significance of strength undermatching of welds in structural behaviour, GKSS Research Center Publications, Geesthacht, FRG, pp. 55-73, 1997.

[5] BLOMQVIST, A., COLLIN, P., and RANBY, A.,Dimensionering av svetsförband $i$ seghärdade konstruktionsstål av Weldox 500 och Weldox 700. Stålbyggnadsinstitutet publikation 156. ISBN 91-7127-1014-0.

[6] Satoh, K., Toyoda, M.,. Joint strength of heavy plates with lower strength weld metal, Welding Research supplement, pp. 311-319, 1975.

[7] TÖRNBLOM, S. Undermatching butt welds in high strength steel, Master's thesis, Luleå University of Technology, Luleå, 2007:220 CIV. 